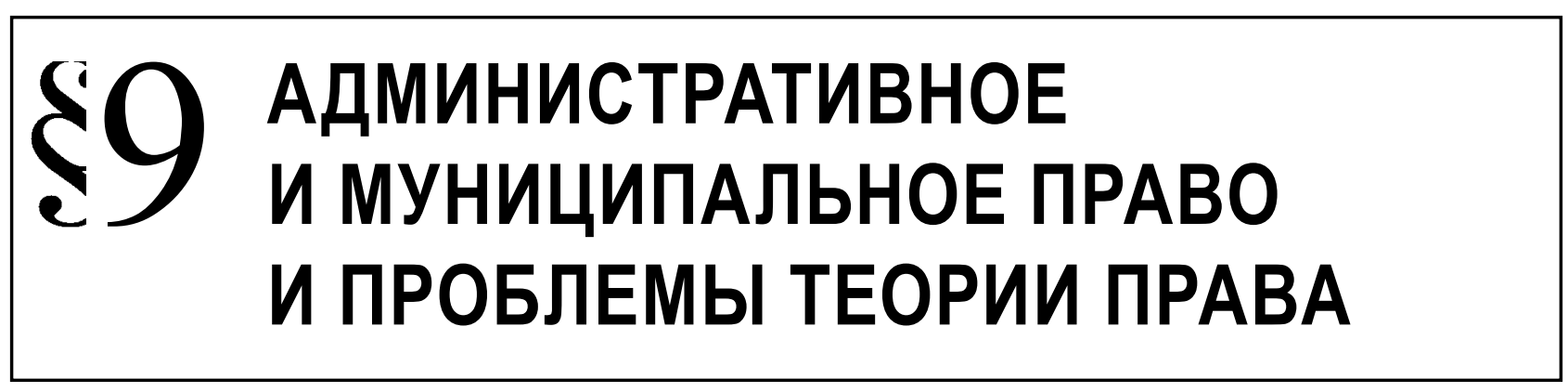

Беляева Г.С.

\title{
К ВОПРОСУ О СУЩНОСТИ И СИСТЕМЕ ПРАВОВЫХ СРЕДСТВ
}

\begin{abstract}
Аннотация: В данной статье рассматриваются вопросы сущности и системы правовых средств, в связи с чем исследуются основные этапы становления теории правовых средств и инструментального подхода в праве. Анализируются взгляды ученых на юридическую природу правовых средств, в результате чего делаются определенные выводы относительно сущности и содержания данного юридического явления. В работе также рассматривается система правовых средств, основания для их классификации и особенности наполнения правового режима как комплексного правового средства первичными юридическими средствами. В работе использованы различные общенаучные приемы и способы логического познания: анализ и синтез, абстрагирование, моделирование, системно-структурный, функциональный и формально-логический подходы. Специальные методы представлены конкретно-социологическим и статистическим, а частнонаучные формально-юридическим, сравнительно-правовым и методом толкования норм права. Новизна исследования заключается в систематизации сущностных характеристик правовых средств и выявлении системообразующих факторов - оснований для классификации правовых средств и особенностей функционирования простых (элементарных) правовых средств в рамках их единых комплексов (правовых режимов). Теоретические суждения автора подтверждаются и иллюстрируются нормативно-правовыми источниками.

Ключевые слова: правовое средство, инструментальная теория права, чель в праве, эффрективность права, система правовых средств, правовой режим, правовой механизм, критерии классификации, первичные правовые средства, комплексные правовые средства.

Review: The article considers the questions of essence and system of legal instruments, the main stages of formation of the theory of legal instruments and the instrumental approach in law. The scientists's views on the legal nature of legal instruments are analyzed, the certain conclusions concerning the essence and the maintenance of this legal phenomenon are made. The author considers the system of legal instruments, the grounds for their classification and the peculiarities of legal order as a complex legal instrument filling with primary legal instruments. The study uses the various general scientific methods and ways of logical cognition: analysis and synthesis, abstraction, modeling, the system and structural, the functional and formal and the logical approaches. The special methods are presented by the special sociological and the statistical methods, and the particular - by the formal-juridical, the comparative and legal and the method legal norns interpretation. The novelty of the research consists in systematization of essensial characteristics of legal instruments and identification of the core factors - the bases for classification of legal instruments and peculiarities of functioning of simple (elementary) legal instruments within their integrated complexes (legal orders). The theoretical judgments of the author are confirmed and illustrated by legal sources.

Keywords: legal mechanism, legal order, system of legal instruments, efficiency of law, purpose in law, instrumental theory of law, legal instrument, criteria of classification, primary legal instruments, complex legal instruments.
\end{abstract}

$\mathrm{H}$ адо сразу заметить, что проблема правовых средств в отечественной юридической науке первоначально возникла и развивалась на стыке актуальных общетеоретических проблем: правового регулирования, его механизма и эффективности права, берущих свои концепту- альные начала в 60-е годы XX века, когда впервые были выработаны понятия механизма правового регулирования, социального действия права, выявлены критерии эффективности в трудах таких ученых, как Н.Г. Александров, С.С. Алексеев, В.Б. Казимирчук, Л.С. Явич и некоторых других. 
В настоящее время теория правовых средств (подчеркнуто нами - Г.Б.) представляет собой самостоятельное перспективное направление в общей теории права, разработке которой в значительной мере служат современные научные труды таких ученых, как С.С. Алексеев, А.В. Малько, Н.И. Матузов, В.А. Сапун, В.М. Сырых, Ю.А. Тихомиров и других.

Как известно, понятие «средство» - общенаучное, междисциплинарное, используемое в различных отраслях знания и имеющее в связи с этим свои особенности. Наряду с этим, достаточно часто понятие «средство» (именно в юридическом значении) встречается в нормативно-правовых актах различного уровня, как международного, так и внутригосударственного.

Например, Конвенция Организации Объединенных Наций о договорах международной куплипродажи товаров (заключена в Вене 11.04.1980) [1] содержит специальный раздел «Средства правовой защиты в случае нарушения договора продавцом». В Конституции РФ содержит положение о том, что «каждый вправе в соответствии с международными договорами Российской Федерации обращаться в межгосударственные органы по защите прав и свобод человека, если исчерпаны все имеющиеся внутригосударственные средства правовой защиты» (ч. 3 ст. 46). Федеральный конституционный закон от 30.05.2001 № 3-ФКЗ «0 чрезвычайном положении» [2] содержит главу, именуемую «Силы и средства, обеспечивающие режим чрезвычайного положения».

Между тем, по свидетельству ряда ученых, категория «правовые средства» до сих пор еще обстоятельно не изучена, употребляется в юридической литературе зачастую произвольно, как сама собой разумеющаяся; под ней понимаются разные правовые явления без определенных смысловых границ, без четкой связи с категориями «цель» и «результат» [3].

Так что же следует понимать под термином правовое (юридическое) средство? Представим свой вариант ответа на поставленный вопрос.

Начнем с упоминания о том, что термин «юридическое средство» впервые встречается в трудах дореволюционных ученых-правоведов (Л.И. Петражицкий, Г.Ф. Шершеневич и другие). В 60-70-е годы XX в. правовые средства, как и многие другие юридические понятия, начали анализироваться в отраслевых дисциплинах: трудовом праве (В.Н. Дивеева, В.Н. Курилов, Ю.П. Орловский, А.А. Шугаев), гражданском (Н.А. Баринов. Ю.А. Огибалин, Б.И. Пу- чинский, Я.Н. Шевченко, М.И. Штефан), уголовнопроцессуальном (П.С. Элькинд). Вместе с тем, по нашему убеждению, проблема правовых средств является, прежде всего, общетеоретической, где также наметились основные подходы: их используют и в отношении к праву в целом (Р.О. Халфина), и в отношении к многообразным режимам правового регулирования, элементам его механизма (С.С. Алексеев, В.И. Гойман, А.В. Малько, Н.И. Матузов, О.С. Родионов, В.А. Сапун, К.В. Шундиков).

В современной юридической литературе под правовыми средствами понимаются различные правовые феномены (нормы права, юридические факты, субъективные права и юридические обязанности, правоотношения, дозволения, заперты, позитивные обязанности и другие).

Многообразие походов и мнений относительно набора тех или иных правовых средств в большей степени зависит от соответствующих отраслей и институтов права. Так, в административном праве, учитывая определенную специфику осуществления управленческой деятельности с целью урегулирования административно-правовых отношений, возникающих в области административно-политического руководства обществом, установлены режимы охраны государственной границы, пограничный режим, режим в пунктах пропуска через государственную границу, режим пребывания иностранных граждан и лиц без гражданства на территории Российской Федерации, посредством введения которых в государстве должен обеспечиваться достаточный уровень личной, общественной и государственной безопасности, необходимый для защиты собственных национальных интересов от любых посягательств со стороны других государств.

Такое разнообразие правовых средств в юридической науке, с одной стороны, признается явлением нормальным. Как справедливо замечает С.C. Алексеев, «вопрос правовых средств, не столько вопрос обособления в особое подразделение тех или иных элементов правовой действительности, сколько вопрос их особого видения в строго определенном ракурсе - их функционального предназначения, их роли как инструментов оптимального решения социальных задач» [4].

Более того, в соответствии с таким подходом высказывается мнение, что рядом с термином «правовые средства» «вполне можно поставить термины «правовые явления», «правовые феномены», «правовые факторы», «правовые условия» и т.п., которые могут считаться взаимозаменяемыми» [5]. 
С другой стороны, существует и такой подход, при котором применение термина «правовое средство» для обозначения любых правовых объектов считается неприемлемым. Так, Б.И. Пугинский возражает против применения термина «правовые средства» по отношению «к юридическим реалиям, имеющим собственные научно определенные понятия» [6]. Обосновывая свою точку зрения, автор ссылается на методологический принцип «Бритва Оккама», согласно которому запрещается введение в научный оборот новых терминов для обозначения объектов, уже поименованных достаточно строго сформулированными понятиями. Таким образом, ученый приходит к выводу о том, что введение понятия «правовое средство» имеет смысл именно в целях отчленения, отграничения правовых норм, институтов и правоотношений от таких реалий, которые не укладываются в содержание традиционных терминов [7].

Избегая крайностей первого и второго подхода, следует сказать, что понятие «правовые средства» позволяет обобщить разнообразные фрагменты правовой действительности: юридические нормы, субъективные права и обязанности, правоотношения, акты реализации права и другие, призванные обеспечить достижение целей правового регулирования. Логично при этом подчеркнуть, что главное научное и практическое прикладное значение правовых средств состоит в том, что они характеризуют функциональную составляющую правовых явлений, составляют их ядро, сердцевину.

По мнению С.С. Алексеева, это предполагает такое применение юридического инструментария к решению экономических и социальных задач, при котором был бы достигнут эффект, реализующий социальную ценность, достоинство права и обеспечивающий сочетание в правовых режимах надежности и устойчивости складывающихся отношений; связи регулирования с субъективными правами; строгих рамок и в то же время гарантированности, защищенности субъективных прав; комплекса надежных способов, гарантирующих реальное (фактическое) исполнения юридических обязанностей; необходимой процедуры для осуществления юридических действий, процессуальных форм и механизмов, нацеленных на реализацию субъективных прав и достижение истины в конфликтных ситуациях[8].

Тем самым правовые средства обеспечивают возможность для усиления позитивных факторов регулятивного воздействия права, устраняя препятствия, снижающие эффективность действия права.
Как верно отмечает В.М. Сырых, эффективно действующие нормы призваны закреплять такие юридические средства, которые позволили бы нейтрализовать негативные факторы и усилить действие позитивных. «В противном случае действие негативных факторов будет более интенсивным, чем правовых средств. Соответственно, и результаты действия норм права будут иными, чем планировал правотворческий орган» [9].

Другими словами, если бы между целью и результатом не было препятствий, не нужны были бы и правовые средства, которые в данном случае являются своеобразной реакцией на возникающие в правовом регулировании препятствия.

В результате можно сказать, что в рамках представленного подхода понятие «правовое средство» имеет ключевое значение для развития так называемого инструментального научного подхода, который раскрывает явления правовой действительности в качестве средств (инструментов) решения различных задач - экономических, организационных, политических, социальных. Всецело разделяем точку зрения В.А. Сапуна, когда он пишет, что «инструментальная теория представляет собой целенаправленное и концентрированное исследование определенного аспекта права как системы правовых средств» [10].

Система юридических средств - сложное, многоуровневое образование. Различный состав, а иногда и уровень правовых средств, которые, заметим, бывают и простыми, и комплексными, предполагает известные трудности при их классификации. Но, поскольку такая классификация имеет как научное, так и прикладное значение, предпримем такую попытку.

С нашей точки зрения, по составу следует различать отдельные правовые средства (первичные, элементарные) и их комплексы.

К первичным правовым средствам относятся дозволения, запреты, обязывания и т.д., из которых, в свою очередь, складываются комплексные правовые средства - нормы права, правовые институты, правоотношения, нормативные и правоприменительные акты, правовые механизмы (механизм правового регулирования, механизм правового воздействия, механизм реализации права, механизм процессуального регулирования и т.д.), правовые режимы и другие.

По значимости все правовые средства можно подразделить на основные (напрямую используемые субъектами права для достижения своих интересов) и вспомогательные (обслуживающие ос- 
новные, содействующие их реализации, - правовые принципы, презумпции, аксиомы, фикции и т.д.).

В зависимости от выполняемой функциональной роли правовые средства делятся на регулятивные (направленные на упорядочение общественных отношений) и охранительные (вступающие в действие при необходимости обеспечить достижение целей правового регулирования при помощи принудительной силы в случае возникновения препятствий различного рода для субъектов права, реализующих свои права и законные интересы).

В свою очередь, охранительные правовые средства можно подразделить на средства-гарантии, направленные на обеспечение реализации права и законных интересов субъектов) и средства государственного принуждения (предупреждения, пресечения, юридической ответственности).

По предмету правового регулирования правовые средства возможно классифицировать на конституционные, административные, уголовные, гражданские и т.п. Так, для административного права характерны такие регулятивные правовые средства, как запрет, обязывание.

В то же время существуют и межотраслевые правовые средства, распространяющие свое действие на несколько отраслей права. Например, такое правовое средство, как договор, используется в конституционном праве (договор о разграничении полномочий между Федерацией и субъектами Федерации), гражданском праве (гражданско-правовой договор купли-продажи), семейном праве (брачный договор), трудовом праве (трудовой договор).

По характеру правовые средства делятся на материально-правовые и процессуальные (иск, следственные действия).

Наряду с изложенными, возможно выделить и другие основания для классификации правовых средств:

- по значимости последствий их можно подразделить на обычные (штраф) и исключительные (смертная казнь);

- $\quad$ по времени действия - на постоянные (гражданство) и временные (премия);

- $\quad$ по виду правового регулирования - на нормативные (закрепленные в нормах права) и индивидуальные (акты реализации права);

- по информационно-психологической направленности - на стимулирующие (льготы) и ограничивающие (запреты).

При характеристике правовых средств, конечно же, нельзя умолчать об их функциях, о значимости и роли таковых.
Вначале заметим, что любое средство существует постольку, поскольку оно служит достижению какой-либо цели. Основной функцией правовых средств по праву можно считать достижение целей правового регулирования: играя роль юридических инструментов в системе правовых явлений, они обеспечивают беспрепятственное достижение субъектами своих интересов, гарантируют их законное и справедливое удовлетворение, нацелены на достижение социально-значимого результата. По верному выражению А.В. Малько, они вносят «цивилизованность в существующие общественные отношения, предлагая вместо незаконных (противоправных) и стихийных (внезаконных - моральных и т.п.) правовые механизмы решения возникающих проблем, правовые способы устранения конфликтов, правовую энергию в преодолении стоящих на пути удовлетворения интересов субъектов права препятствий»[11].

Таким образом, правовые средства представляют собой правовые явления (установления, деяния), с помощью которых достигаются цели правового регулирования, социально-значимый результат.

Уделим некоторое внимание и такому комплексному правовому средству как правовой режим.

Поскольку правовой режим представляет собой сложную, комплексную, высокоорганизованную систему, логично включение в его структуру правовых средств различных уровней.

С нашей точки зрения, обоснованным представляется подход С.С. Алексеева, который выделяет в общем наборе правовых средств:

- уровень первичных правовых средств - элементов механизма правового регулирования в целом и его важнейших подразделений (юридические нормы, субъективные юридические права и юридические обязанности);

- уровень целостных правовых режимов (правовые средства, которые обеспечивают льготный или ограничительный порядок регулирования);

- уровень операционного юридического инструментария (правовые средства, которые используются в оперативной деятельности государственных органов, предприятий, учреждений, организаций, должностных лиц, граждан, - договоры, иски, штрафы, жалобы, - служащие вспомогательным связующим звеном между этапными блоками основных правовых средств, объединенных в правовых режимах) [12]. 
Полагаем, что, если исходить из деления правовых средств по субстанциональным уровням, то в рамках правового режима целесообразно выделение трех групп структурных элементов.

Первую группу составляют элементы механизма правового регулирования - нормы права, юридические факты, правоотношения, акты реализации права, правоприменительные акты, который, в свою очередь, также является комплексным правовым средством. Данная группа правовых средств составляет «механизм» правового режима, посредством которого реализуются его функции.

Нормы права в составе правового режима определяют модель поведения субъекта в режимной ситуации, время, место, условия ее наступления, правила поведения, права и обязанности субъектов по отношению к объектам правового регулирования, возможные санкции (положительные или отрицательные).

Юридические факты в правовом режиме являются звеном, связывающим норму права и правоотношение. Здесь он играет двоякую роль: во-первых, юридические факты «включают» правовой режим, помогают перейти ему из сферы возможного в сферу сущего; во-вторых, уже в рамках существующих режимных отношений - могут менять их специфику. Например, в первом случае заключение брака (как юридический факт) является основанием для введения в действие законного режима имущества супругов (гл. 7 Семейного кодекса РФ). Во втором случае, заключение брачного договора между супругами (как юридический факт) влечет изменение законного режима имущества супругов на договорный (гл. 8 Семейного кодекса РФ).

Следующим элементом данной группы правовых средств в составе правового режима, конечно же, выступают правовые отношения. В рамках правового режима правоотношения играют особую роль, во многом определяя его сущность, сферу действия и функциональную направленность.

В свою очередь, правоотношения представляют собой комплексное правовое средство, одни элементы которого (например, субъективные права и юридические обязанности) сами по себе являются самостоятельными правовыми инструментами, а другие (субъекты и объекты правоотношения) - самостоятельными образованиями.

Надо заметить, что определенную дискуссионность вызывает вопрос включения субъектов права (правоотношений) в материю правового режима. Полагаем, что субъекты права однозначно могут быть включены в структуру правоотношения в качестве элемента правового режима. Однако в содержании самого правового режима данный элемент будет играть определяющую роль не во всех, а только в строго установленных случаях, когда правовой режим устанавливается не относительно определенных объектов правового регулирования и видов деятельности, а в отношении субъектов права (иностранных граждан, лиц без гражданства, беженцев, вынужденных переселенцев т.д.), то есть, условно говоря, когда эти субъекты переходят в ранг определяющего объекта регулирования данного правового режима.

При характеристике объектов правоотношений в составе правового режима следует привлечь внимание к наличию как основных объектов, по поводу которых возникает правовой режим, так и дополнительных (вспомогательных) объектов, входящих в состав правового режима в рамках соответствующих правоотношений и не оказывающих прямого воздействия на правовой режим в целом. Например, глава XIV Земельного кодекса РФ регламентирует правовой режим земель сельскохозяйственного назначения. Это основной объект в рамках данного правового режима. В ст. 81 Земельного кодекса РФ закреплена возможность предоставления земель сельскохозяйственного назначения гражданам для ведения крестьянского (фермерского) хозяйства и личного подсобного хозяйства. Следовательно, земли, предоставленные гражданам для вышеназванных целей (если такое предоставление состоится и соответствующие правоотношения заработают) будут составлять основной объект соответствующих правоотношений и вспомогательный объект правового режима земель сельскохозяйственного назначения.

Акты реализации права как структурный элемент правового режима, складывающийся уже в процессе его действия, имеют целью обеспечить воплощение в жизнь самого правового режима.

Вторую группу составляют правовые средства, обеспечивающие, по мысли С.С. Алексеева, льготный или ограничительный порядок регулирования [13]; в нашей терминологии - порядок, основанный на установлении преимуществ или ограничений, дозволений и запретов, иных способов правового воздействия и их особом сочетании.

Если правовые средства, представленные в первой группе, отвечают за создание особой направленности правового регулирования в рамках правового режима, то рассматриваемые правовые средства характеризуют степень благоприятности 
(неблагоприятности) правового режима для удовлетворения интересов субъектов права.

Преобладание дозволений или ограничений (в том числе запретов) в рамках того или иного правового режима во многом определяется сферой его действия - отраслью права и методом ее регулирования. Так, в конституционном, административном, уголовном, уголовно-исполнительном и всех процессуальных отраслях права будут действовать правовые режимы, в основном построенные на ограничениях (жесткие режимы). Например, административно-правовой режим чрезвычайного положения является жестким правовым режимом. Это следует из ст. 1 Федерального конституционного закона от 30.05.2001 № 3-ФКЗ «0 чрезвычайном положении»: «Чрезвычайное положение означает вводимый в соответствии с Конституцией Российской Федерации и настоящим Федеральным конституционным законом на всей территории Российской Федерации или в ее отдельных местностях особый правовой режим деятельности органов государственной власти, органов местного самоуправления, организаций независимо от организационно-правовых форм и форм собственности, их должностных лиц, общественных объединений, допускающий установленные настоящим Федеральным конституционным законом отдельные ограничения прав и свобод граждан Российской Федерации, иностранных граждан, лиц без гражданства, прав организаций и общественных объединений, а также возложение на них дополнительных обязанностей» (подчеркнуто мною - Г.Б.).

Соответственно, в гражданском, семейном, трудовом праве будут преобладать режимы, основанные на дозволениях (мягкие режимы). Например, правовые режимы сделок в гражданском праве являются мягкими правовыми режимами, поскольку, как следует, из содержания большинства гражданско-правовых норм, базируются на договорных отношениях между сторонами.

Это, однако, не означает отсутствие в публичных отраслях права мягких режимов и наоборот; просто одни режимы в регулируемых отношениях будут играть роль основных, а вторые - вспомогательных.
Так, правовой режим имущества подопечных, установленный Федеральным законом от 24.04.2008 № 48-Ф3 «Об опеке и попечительстве» [14], принадлежащий к гражданскому праву, является жестким, основанным на ограничениях (запретах).

Третья группа правовых средств выполняет вспомогательную функцию, и ее составляют операциональные правовые средства - самостоятельные юридические инструменты, способные обеспечить работу правового режима непосредственно (жалоба, штраф, иск, договор, протест, ходатайство). Например, брачный договор является самостоятельным юридическим инструментом в договорном режиме имущества супругов в семейном праве, иск - в процессуально-правовом режиме искового производства в гражданско-процессуальном праве; представление прокурора - в процессуально-правовом режиме производства в суде кассационной инстанции в гражданско-процессуальном праве и т.д.

Подводя некоторый итог, отметим, что правовые средства, несмотря на свое многообразие, имеют ряд общих черт, позволяющих объединить их в одну группу в системе правовых явлений. Само же рассмотрение явлений правовой действительности в качестве правовых средств и их комплексов (юридических механизмов, правовых режимов) нацеливает правоведов на то, чтобы было возможно предельно полно изучить их возможности для эффективного решения основных задач государства. В этом и заключается, по нашему мнению, плодотворная и социально востребованная перспектива развития отечественной юридической науки - поставить ее на более действенную службу практики для решения крупных проблем социальной действительности: оптимизации правового регулирования, настроя российской правовой системы на социально плодотворную работу. Следовательно, есть все основания полагать, что проблема своевременного и качественного совершенствования правовых средств, оптимального их сочетания в механизмах правового регулирования и правовых режимах становится все более актуальной, научно и практически значимой.

\section{Библиография:}

1. Малько А.В. Правовые средства: вопросы теории и практики // Журнал российского права. 1998 . № 8.

2. Мурсалимов Г.Р. Методология понимания технико-юридических средств преодоления правоприменительных ошибок // История государства и права. 2007. № 16.

3. Алексеев С.С. Правовые средства: постановка проблемы, понятие, классификация // Советское государство и право. 1987. № 6.

4. Проблемы теории государства и права: Учебное пособие / Под ред. М.Н. Марченко. М., 2003. 
Административное и муниципальное право 3 (87) 2015

5. Алексеев С.С. Теория права. 2-е изд. М., 1995.

6. Сырых В.М. Истинность и правильность как критерии теоретической эффективности норм права //Эффективность закона /под ред. Ю.А. Тихомирова. М., 1997.

7. Сапун В.А. Инструментальная теория права в юридической науке //Современное государство и право: вопросы теории и истории. Владивосток, 1992.

8. Алексеев С.С. Правовые средства: постановка проблемы, понятие, классификация // Советское государство и право. 1987. № 6.

9. Беляева Г.С. Правовой режим в общетеоретическом измерении: монография. М., 2013.

10. Беляева Г.С. Правовой режим: общетеоретическое исследование: Автореф. дисс. ... докт. юрид. наук. Курск, 2013.

11. Брыксина Г.С. Проблемы теории правового режима органа государственной власти: Дисс. ... канд. юрид. наук. Тамбов, 2004.

12. Беляева Г.С. Правовые режимы, основанные на преимуществах: к вопросу о понятии // Административное и муниципальное право.-2014.-10.-C. 1073-1080. DOI: 10.7256/1999-2807.2014.10.12288.

13. Беляева Г.С. К вопросу о понятии правового режима // Административное и муниципальное право.-2014.-3.C. 272-285. DOI: 10.7256/1999-2807.2014.3.10938.

\section{References (transliterated):}

1. Mal'ko A.V. Pravovye sredstva: voprosy teorii i praktiki // Zhurnal rossiiskogo prava. 1998. № 8.

2. Mursalimov G.R. Metodologiya ponimaniya tekhniko-yuridicheskikh sredstv preodoleniya pravoprimenitel'nykh oshibok // Istoriya gosudarstva i prava. 2007. № 16.

3. Alekseev S.S. Pravovye sredstva: postanovka problemy, ponyatie, klassifikatsiya //Sovetskoe gosudarstvo i pravo. 1987 . № 6.

4. Problemy teorii gosudarstva i prava: Uchebnoe posobie / Pod red. M.N. Marchenko. M., 2003.

5. Alekseev S.S. Teoriya prava. 2-e izd. M., 1995.

6. Syrykh V.M. Istinnost' i pravil'nost' kak kriterii teoreticheskoi effektivnosti norm prava //Effektivnost' zakona /pod red. Yu.A. Tikhomirova. M., 1997.

7. Sapun V.A. Instrumental'naya teoriya prava v yuridicheskoi nauke //Sovremennoe gosudarstvo i pravo: voprosy teorii i istorii. Vladivostok, 1992.

8. Alekseev S.S. Pravovye sredstva: postanovka problemy, ponyatie, klassifikatsiya // Sovetskoe gosudarstvo i pravo. 1987 . № 6.

9. Belyaeva G.S. Pravovoi rezhim v obshcheteoreticheskom izmerenii: monografiya. M., 2013.

10. Belyaeva G.S. Pravovoi rezhim: obshcheteoreticheskoe issledovanie: Avtoref. diss. ... dokt. yurid. nauk. Kursk, 2013.

11. Bryksina G.S. Problemy teorii pravovogo rezhima organa gosudarstvennoi vlasti: Diss. ... kand. yurid. nauk. Tambov, 2004.

12. Belyaeva G.S. Pravovye rezhimy, osnovannye na preimushchestvakh: k voprosu o ponyatii // Administrativnoe i munitsipal'noe pravo.-2014.-10.-C. 1073-1080. DOI: 10.7256/1999-2807.2014.10.12288.

13. Belyaeva G.S. K voprosu o ponyatii pravovogo rezhima // Administrativnoe i munitsipal'noe pravo.-2014.-3.-C. 272-285. DOI: 10.7256/1999-2807.2014.3.10938. 